\title{
Perceived Effectiveness Of Personalization
}

Sujata Ramnarayan, (Email: ramnar_s@cob.sjsu.edu), San Jose State University

\begin{abstract}
The internet, while still in infancy, has established itself as a channel for commerce and communication. The interactive nature of its network, along with size and speed is leading to a paradigm shift in the way companies approach the marketing mix, similar to the shift in thinking from a production/sales orientation to a customer orientation to a future defined by personalization. There are currently very few empirical studies focusing on the construct and practice of personalization in the academic literature. This study empirically tests the perceived effectiveness of personalization based on an online survey of approximately 200 marketing executives on a business panel. As predicted, personalization was perceived as having a positive impact on both profit and customer responsiveness for the company.
\end{abstract}

\section{INTRODUCTION}

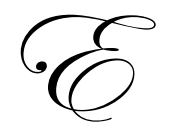

-commerce continues to grow even when the U.S. economy, in general, has been in recession for the past few years. The internet while still in its infancy, has clearly established itself as a channel for commerce and communication. It is characterized by network interactivity, size, and speed (Coupey 2001). Its interactive nature and the ability to track consumers easily as data points makes it possible to make the customer a co-creator in the development of the marketing mix (Krishnamurthy 2003). This allows for the use of technology and customer information obtained either explicitly or implicitly to tailor interactions between businesses and individual consumers. This is equivalent to a paradigm shift in the way companies approach their marketing mix, similar to the shift in thinking from a production/sales orientation to a customer orientation. While traditional marketing has focused on exchanges, e-marketing's focus is on relational exchanges in a networked world of which personalization is an important and central element (Kalyanam and McIntyre 2002).

\section{PARADIGM SHIFT FROM MARKET ORIENTATION TO PERSONALIZATION}

Looking back at the history of marketing (See Figure1), it is clear that companies have come a long way from mass marketing of Model Ts enabled by industrial production to target marketing enabled by creation of databases to mass customization enabled by technology to an era of personalization enabled by the interactive nature of the internet as well as other technologies. Over the last few decades, there has been a gradual move in marketing thought and practice from mass marketing to market segmentation to niche marketing to micro-marketing to masscustomization to personalization (Goldsmith 1999). Personalization is a special form of differentiation that changes product design from an inherent compromise to a process of deciding what features would benefit an individual (Hanson 2000). Unlike 1:1 marketing (Peppers and Rogers 1999), personalization has the potential to turn customers into co-creators of the marketing mix (Krishnamurthy 2003).

Personalization has been defined as targeting to wafer thin slices of market and, at an extreme, to one individual at a time. It is a toolbox of technologies and application features used in the design of a unique end-user experience. Personalization is about building customer loyalty by building a meaningful one-to-one relationship; by understanding the needs of each individual (customer) and helping satisfy a goal that efficiently and knowledgeably addresses each individual/customer's need (Reicken 2000). Personalization, according to Peppers and Rogers (1999) involves treating each visitor as an individual, recognizing visitors when they revisit a site, and serving information based on his/her explicit or implicitly stated preferences. The term personalization is defined here as targeting to a segment of one or a small subset of individuals based on implicitly or explicitly stated preferences. The term "subset" was added to reflect the way it is currently being practiced by organizations. This subset is still a sliver compared to segments typically targeted under the practice of target marketing. It is also different from one-to-one marketing in 
the extent to which it takes customer preferences into account. To date, there are very few empirical studies that focus on the personalization construct and its practice by companies. This study is proposed as a way to understand the perceived effectiveness of personalization from the company's perspective.

Figure 1

History of Marketing

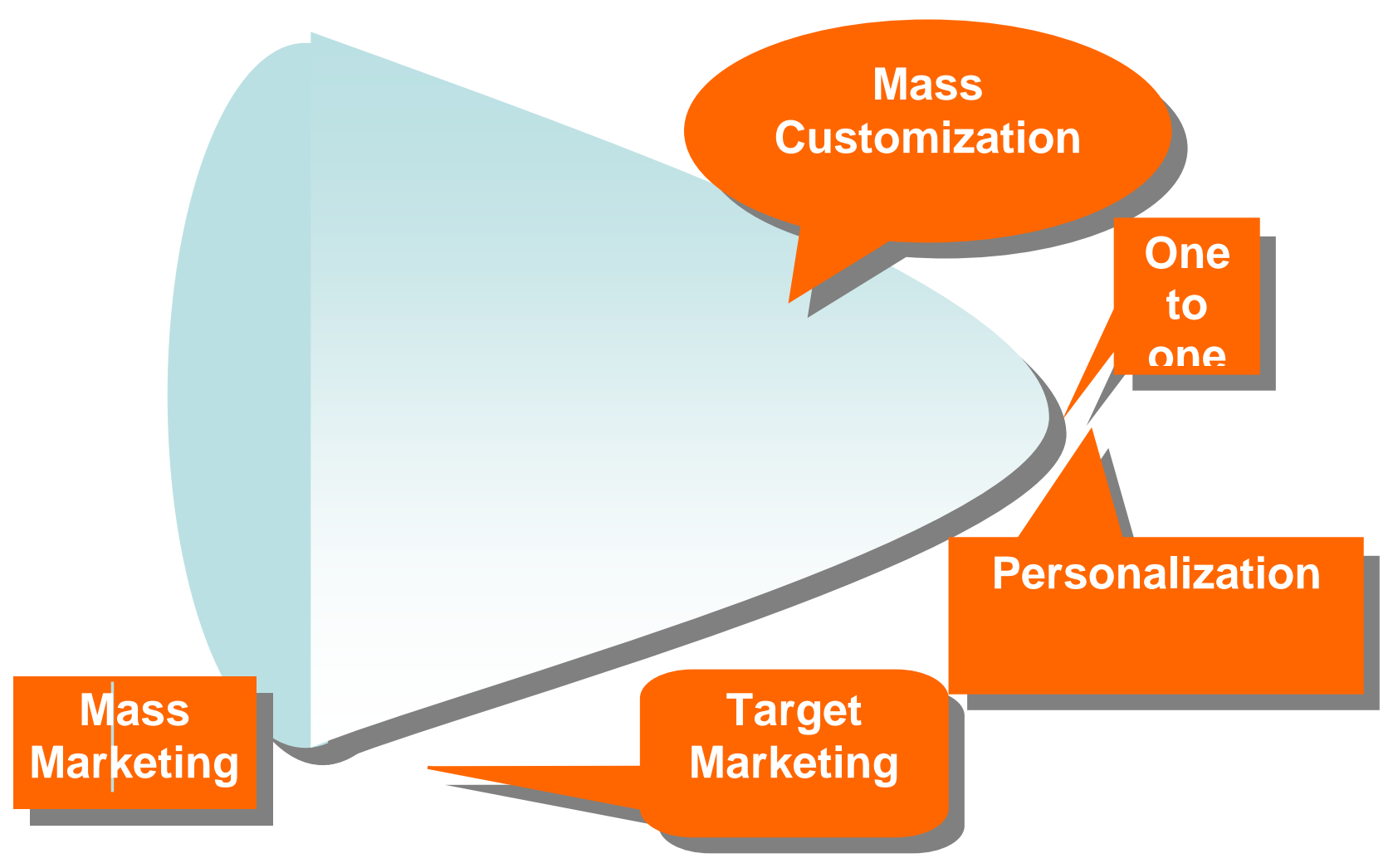

\section{LITERATURE REVIEW AND CONCEPTUALIZATION OF PERSONALIZATION}

Personalization has been identified as one of the constructs having an impact on customer perception of website effectiveness (Chakraborthy et. al. 2002); It is also seen as a way to help customers find what they don't know (Belkin 2000). In many cases, customers do not have the ability to query information retrieval systems with the most contextually appropriate keywords. In such cases, personalization through a feedback system of query reformulation is effective (Belkin 2000). Gilmore and Pine (1997) proposed different approaches to implementation of personalization. Theirs is a conceptual piece with case study examples describing four different approaches to customization by changing either the product only, representation only, changing both or neither. As the authors state, personalization can be implemented either by conducting a dialogue with a customer, simply and silently observing a customer, by displaying uniqueness or by embedding it. In other words, even the best suited personalization approach could be different for each customer. Personalization systems to date have generally involved manual decision rule systems (e.g. using demographic or registration data to set up rules) such as from Broadvision; collaborative or content based filtering systems (Mobasher et al 2000). Collaborative filtering systems use a correlation engine to return information predicted to match explicit user ratings or preferences. Content filtering approaches use content similarity of web documents to profiles obtained explicitly or implicitly from the user. Thus the approaches to personalization are based on implicit or explicit or both types of information obtained from the user. 
The differences between mass customization, personalization, 1:1 marketing, and the potential for personalization to move towards a stage of "customerization" are well captured by Wind and Rangaswamy (2001). The term mass customization has been defined as using flexible processes and organizational structures to produce varied and often individually customized products and services at the price of standardized mass produced alternatives (Hart 1996). Thus, it's focus is on an IT intensive production end as opposed to being buyer centric. Personalization and customerization are both IT intensive on the marketing/ customer interface end. However, Wind and Rangaswamy (2001) differentiate customerization from personalization as a purely build to order customer initiated phenomenon that requires a high level of both operational and marketing customization. In other words, personalization is a necessary but not sufficient aspect of customerization. As Wind and Rangaswamy point out, customerization requires effective integration of marketing, operations, finance, R\&D, manufacturing, and information along with being driven by customers before the product is built. A recent study by McKenzie (2003) found that the productivity levels achieved by Dell far surpass companies such as Intel and Cisco due to streamlining of its business operations along with a build to order model. What Dell offers currently at its customer interface is "adaptive personalization" where the customer chooses from a set of options. For its business customers, it has created 30,000 password protected sites along with personalization of product options and pricing. Dell is going one step further in building a very detailed database of services provided by its partners to its business customers, an example of how it hopes to gain from digitizing as many of its business processes as possible in the greatest possible detail (Wall Street Journal, Nov 11, 2003). Personalization could be initiated by the customer, the company, or both. In personalization, the message/product is tailored for an individual customer. Although, it could potentially apply to distribution (e.g. SafeWay.com provides three different alternatives to its customers - shopping and delivery to home, customer shopping, pick-up only) or even to pricing (the best example today being one of auctions), the most common applications of personalization seen today are in the arena of product and communication. For example, keyword advertising through search engines is an example of implicit form of personalized communication. On the other hand, my yahoo! Website is an example of explicitly chosen and adapted form of personalized product.

The internet makes it possible to understand consumer behavior at a personal level. Companies differ in its implementation today both in context and degree. The context can include an online or brick and mortar setting. It's implementation could also differ in degrees from a low to a high level of personalization. For example, personalization need not be limited to an online environment. It could be in an offline context as well, such as when a SafeWay employee thanks each consumer by name at the cash register. This is a low level of personalization in an offline context. What differentiates "online personalization" is the ability to track user browsing behavior down to individual mouse clicks. This provides richer information with the potential to bring companies and customers closer than ever before. A low level of personalization in an online context could be sending personal emails to prospects and customers addressing each by name. A higher degree of personalization in the same context could include sending articles of interest or special deals by email to prospects/customers based on an understanding of their prior online behavior.

\section{OPERATIONALIZATION OF PERSONALIZATION CONSTRUCT}

Taking the above aspects into account, personalization was operationalized as a multi-item construct reflecting the possibility of implicit or explicit implementation and its implementation by dynamically changing either content or message, or a simple implementation such as greeting by individual's name (Appendix A). As shown is Appendix A, personalization was measured as a multi-item measure that was recorded on a binary scale based on whether or not the company was currently using a particular personalization technique. These techniques could be as simple as greeting a person by name or as sophisticated as using a collaborative engine to correlate based on similarities and then make recommendations.

\section{PERCEIVED EFFECTIVENESS OF PERSONALIZATION}

There are a number of marketing scholars who espouse personalization and the benefits of one to one marketing to customers. However, empirical data on its benefits to companies remains thin. A few have considered the impact of personalized mail (Byrom and Bennison 2000; Wunder and Wynn 1988; Kahle and Sales 1978) and promotion (Morris-Lee 2002) and of service encounters (Suprenant and Solomon 1987) on marketing effectiveness. 
In the study on service encounters, Suprenant and Solomon (1987) show how effectiveness of personalization varies depending on the type of personalization used. The authors consider three types of personalization in a service encounter: "option" which is equivalent to outcome or product personalization, "programmed" which is equivalent to cosmetic personalization and "customized" personalization which is most extensive. The authors found that customized personalization is more effective in terms of satisfaction, relative to the other two. Not only does the type of personalization have an impact on satisfaction, but also the level of personalization employed with a high level not always being the preferred option. However, this study was an evaluation of personalization of service encounters offline. As this study suggests there are differences in the type of personalization that customers consider beneficial. About $93 \%$ of consumers report customizing at least one site and 25\% report customizing four or more sites (Nunes and Kambil 2001). However, such customization was done by consumers themselves. This study found that most consumers value some filtering of the product selection based on their profile. The authors report that most valued some control over the filtering process. In a separate study of financial services customers (Coner 2003), customers reported preferring a site over which they had control over preferences rather than have the company personalize the site on their behalf based on implicit preferences. However, both these studies were done to assess what consumers prefer between a user controlled versus user unaware personalization, sometimes referred to in the literature as customization versus personalization. Although many consumers expressed a preference for control, this suggests consumer concerns about privacy, and does not run counter to customers finding the outcome of automatic personalization beneficial. In addition, both studies indicate that filtering of information on a website is important to customers. According to Yahoo Chief Scientist, Udi Manber, although most consumers appear to not personalize their My Yahoo page, power users do seem to customize the pages for themselves. This could be due to a combination of reasons including difficulty with the tools themselves (Manger et al 2000).

In a study of factors leading to effectiveness of BtoB websites, Chakraborthy et al (2002) showed that personalization, along with factors such as informativeness, organization, and transaction related interactivity were significant predictors of website effectiveness. Thus, there is evidence to suggest that personalization contributes to customer's perception of website effectiveness. However, Chakraborthy et.al. (2002) measured website effectiveness in terms of customer perception of a website relative to others within the construction industry. Thus, it was focused on the construction industry and measured website effectiveness from the customer's viewpoint. In addition, the authors treated personalization as a two-item construct whereby the customer feels special due to the resulting treatment such as greeting or feels greater satisfaction due to the ability to control or adapt preferences, both being examples of situations where the customer is aware of the individualized treatment. There is a third dimension to personalization which results in modification of either the product or its representation without the customer's awareness, which was not captured in the abovementioned study. This study looks at factors of importance to a company when measuring the outcome of personalization itself. While previous research clearly suggests that personalization is an antecedent to website effectiveness of BtoB websites from a customer's viewpoint, it's perceived effectiveness has not been evaluated from the company's perception. This study considers the perceived effectiveness of personalization of a website in terms of importance to the company. A number of benefits of personalization have been proposed by companies selling the technology that would enable personalization such as increased sales, more efficient use of customer/partner/salespeople time, improved website effectiveness as reflected by time spent by customers, registration rates etc. Based on the above criteria, perceived effectiveness of personalization was operationalized as a multiitem construct reflecting these dimensions (Appendix A). These items, as shown, were measured on a likert scale of 1 to 7 where ' 1 ' meant "no potential to improve the effectiveness of the organization's marketing efforts," and ' 7 ' meant "high potential to improve the effectiveness of the organization's marketing efforts,"

\section{SURVEY METHODOLOGY AND SAMPLE CHARACTERISTICS}

The study was conducted using a survey questionnaire. The survey was conducted online. The sample consisted of a business panel of 2000 marketing executives put together by GartnerG2 (a division of world renowned technology research firm Gartner). The survey only included companies that had a marketing budget of $\$ 50$ million or more. The response rate was $10 \%$ with 207 responses. 


\section{FACTOR ANALYSES}

Before testing of the hypotheses, it was necessary to purify and validate the operationalization of "personalization" and "perceived effectiveness" of personalization constructs . The sample was split in half as holdout and validation samples. Principal component analysis with oblique rotation on the first half yielded 6 factors with eigen values equal to or greater than one accounting for $69 \%$ of the variance in the data. The scree test showed a similar pattern with possibly five factors. The Bartlett's test of sphericity was significant ( $p=.000$; chi-square 453 , df 153) with MSA of 0.64 which is a reasonable fit. A look at the factor loading showed one item (reduced cost) with cross loadings and was dropped from subsequent analysis. All other items had loadings of close to .40 or above. The items "More efficient use of partner time; customer time; employee time" all loaded on one factor labeled as "Customer responsiveness". The items related to "profit" (Customer retention; margin on average sale; overall increase in revenues) all loaded on a second factor. All items related to "Customer Share" (Website registration, number of visitors, increased time) showed significant loadings on a third factor. Thus, perceived effectiveness appeared to be a three dimensional construct with "Customer responsiveness", "profit", and "customer share" as its components. Although there were six factors with eigen values greater than one, it was felt that a five factor solution was more appropriate. For the personalization construct, when factor analysis was restricted to five factors, almost all but "registration" and "Address by name in electronic communications" fell on one factor with registration and "address by name" loading on a second factor. All factor loading were significant (.40 or above). However, it was felt that this was possibly due to the fact that they were related to explicit form of personalization. While the variable, "give control over preferences" was expected to load on this factor, it had cross loadings. However, conceptually, it was felt that it belonged to this factor. In addition, dropping the variable reduced the overall fit of the model.

A second confirmatory factor analysis (Table 1) on the second half of the data confirmed a five factor solution. The Bartlett's test of sphericity was significant $(\mathrm{p}=.000$; chi-square $=505, \mathrm{df}=136)$ and MSA of 0.67 indicating a reasonable fit. As before, perceived effectiveness of personalization revealed a three factor structure. Personalization, although a two factor structure, was treated as a single factor since it was felt that the items on the second factor were all related to both offline and online media, and possibly were loading on the same factor due to this reason. All factor loadings were statistically significant (greater than 0.40).

Table 1

Confirmatory Factor Analysis on Validation Sample

\begin{tabular}{|l|c|c|c|c|c|}
\hline Variable & Factor 1 & Factor 2 & Factor 3 & Factor 4 & Factor 5 \\
\hline Clickstream & .72 & & & & \\
\hline Keyword Query & .72 & & & & \\
\hline Collaborative Filtering & .77 & & & & \\
\hline Control & .60 & & & & \\
\hline Address by name & & .88 & & & \\
\hline Geographic & & .44 & & & \\
\hline Demographic & & .48 & & & \\
\hline Customer Retention & & & .66 & & \\
\hline Margin on average sales & & & .81 & & \\
\hline Overall increase in revenues & & & .80 & & \\
\hline Efficient use of customer/prospect time & & & & \\
\hline Efficient use of partner time & & & & .65 \\
\hline Efficient use of employee time & & & & .79 \\
\hline Increased website registration & & & & \\
\hline Increased number of visitors & & & & \\
\hline Increased time spent by visitors & & & & \\
\hline Factors and corresponding Reliabilities & & & & \\
\hline
\end{tabular}




\section{HYPOTHESES}

As discussed earlier, the key hypothesis in this study was that perceived effectiveness of personalization should increase with extent of personalization. As the factor analyses indicated, perceived effectiveness of personalization is a three dimensional construct with profit, customer responsiveness, and share of customer as the underlying dimensions. Thus as the extent of personalization increases, companies should see an increase in profit, an increase in the ability to respond to customers quickly and an increase in the share of customer time given to their company as indicated by time spent on the website, increased number of visitors at the website and/or increased registrations.

Hypothesis1: Perceived effectiveness of personalization as measured by profit should increase as extent of personalization increases.

Hypothesis 2: Perceived effectiveness of personalization as measured by "responsiveness to customers" should increase as extent of personalization increases.

Hypothesis 3: Perceived effectiveness of personalization as measured by "customer share" should increase as extent of personalization increases.

\section{DISCUSSION OF RESULTS}

Personalization was treated as a summated measure. The dependent measures of Profit, Customer responsiveness, and customer share were all summated measures of items loading on each separate factor. All four measures had reliabilities exceeding .70. Three separate linear regressions were performed with extent of personalization as the independent variable and each of the dependent measures of profit, customer responsiveness and customer share. Table 2 shows the regression coefficients and t-statistic for each of the regressions. As Table 2 shows, hypotheses 1 and 2 were supported, with extent of personalization positively related to customer responsiveness and to profit. However, hypothesis 3 was not supported and extent of personalization did not appear to be significantly positively related to customer share. The adjusted R-squared value in each case was fairly low (3\%).

Table 2

Linear Regression Results of Relationships between Personalization and its Perceived Effectiveness

\begin{tabular}{|c|c|c|}
\hline \multicolumn{2}{|c|}{ Independent Variable: Extent of Personalization } \\
\hline Dependent Variables & Standardized Coefficient & 2.35 \\
\hline Profit & $0.18(\mathrm{p}=0.02)^{*}$ & 2.59 \\
\hline Customer Responsiveness & $0.20(\mathrm{p}=0.01)^{*}$ & 1.17 \\
\hline Customer Share & $0.09(\mathrm{p}=0.24)$ & tistic \\
\hline
\end{tabular}

Table 3 shows the means and standard deviations on the dependent variables of Customer response, profit, and customer share by extent of personalization. The sample was categorized as having a low level of personalization if they mentioned having implemented at least one or no personalization technique. This categorization was based on a median value of 2 for the sample. As shown in the table, in general, the group with higher level of personalization also had higher means on the dependent measures of customer responsiveness (15.19 vs $14.03 ; \mathrm{p}=.045)$, profit (15.79 vs $14.65 ; \mathrm{p}=.042)$, and customer share ( 15.63 vs $15.5 ; \mathrm{p}=0.82)$ compared to the group with a low level of personalization. As seen in the regression results, both hypotheses 1 and 2 were supported.

\section{CONCLUSIONS AND FUTURE RESEARCH IMPLICATIONS}

Research on the impact of personalization is limited in the academic area. This study's contribution is in approaching the construct from the company's perspective and measuring its impact on a company's profit, its ability to get more customers, and its ability to be responsive to customers. As the results show, there is partial support that personalization does have an impact on perceived effectiveness of marketing efforts as measured by profit, customer share, and customer responsiveness. This study used a real world sample of corporate executives to gauge the perception of effectiveness of personalization. 
Table 3

Comparison of Means

\begin{tabular}{|c|c|c|c|}
\hline \multicolumn{4}{|c|}{ Independent Variable: Extent of Personalization } \\
\hline Dependent Variable & $\begin{array}{l}\text { Low (less than equal to 1) } \\
\text { Mean; Std. dev }\end{array}$ & $\begin{array}{l}\text { High(greater than 1) } \\
\text { Mean; Std. dev }\end{array}$ & $\mathrm{F}(1, \mathrm{df}) ; \mathrm{p}$ \\
\hline Profit & $14.03 ; 4.01$ & $15.19 ; 3.22$ & $\begin{array}{c}4.07(1,163) \\
p=0.045^{*}\end{array}$ \\
\hline Customer Responsiveness & $14.65 ; 3.73$ & $15.79 ; 3.24$ & $\begin{array}{c}4.03(1,156) \\
\mathrm{p}=0.042^{*}\end{array}$ \\
\hline Customer Share & $15.5 ; 4.00$ & $15.63 ; 3.12$ & $\begin{array}{c}0.051(1,155) \\
p=0.821\end{array}$ \\
\hline
\end{tabular}

There are a few limitations of this study. Although the sample consisted of corporate executives, it only measured their perceptions of effectiveness of personalization. Future studies should measure actual profits before and after implementation of personalization techniques for a single company. Also, since the techniques used by each company is different, the type of technique used and therefore, its effectiveness, could also vary. This is an aspect that the current study did not control for. Future studies should test for effectiveness of each of the techniques on increase in profit, customer share, and customer responsiveness.

At least $13 \%$ of the respondents mentioned not using any personalization technique and the majority used only simple personalization techniques. This could be a reflection of the difficulty of incorporating such technologies across a heterogeneous set of organizational and technical conditions (Schubert and Leimstoll 2004). Most companies, however, recognized the importance of using such techniques in the future and plan to make substantial investments in this area. This was also a finding in Schubert and Leimstoll's study. Future studies should examine how sophisticated personalization techniques such as the use of collaborative engines have an impact on a company's bottomline.

\section{References}

1. Belkin, Nicholas J. (2000), Helping people find what they don't know, Association for Computing Machinery. Communications of the ACM, August, Vol. 43 (8), 53-61.

2. Byrom, John and David Bennison (2000), The effect of personalisation on mailed questionnaire response rates, International Journal of Market Research, Summer, Vol. 42(3), 357-??

3. Chakraborthy, Goutam, Vishal Lala, and David Warren, An empirical investigation of antecedents of B2B Websites' effectiveness, Journal of Interactive Marketing, Autumn 2002, Vol. 16, Issue 4, 51-72.

4. Coner, Altan (2003), Personalization and customization in financial portals, Journal of American Academy of Business, Vol. 2(2), 498-504.

5. Coupey, Eloise (2001), Marketing and the Internet: Conceptual Foundations, Prentice Hall Inc.

6. Gilmore, James H. and B. Joseph Pine, II (1997), Four faces of customization, Harvard Business Review, Jan-Feb, 91-101.

7. Goldsmith, Ronald. E. (1999), Beyond the 4Ps, Marketing Intelligence and Planning, Vol. 17 (4), 178.

8. Hanson, Ward (2000), Principles of Internet Marketing, South-Western College Publishing.

9. Kahle, Lynn R. and Bruce D. Sales (1978), Personalization of the Outside Envelope in Mail Surveys, Public Opinion Quarterly, 42, 547-550.

10. Kalyanam, Kirthi and Shelby McIntyre (2002), The e-Marketing Mix: A contribution of the e-tailing wars, Academy of Marketing Science Journal. Greenvale: Fall Vol. 30, Issue 4; p. 487-500.

11. Krishnamurthy, Sandeep (2003), E-Commerce Management: Text and Cases, Thomson Learning.

12. Manber, Udi, Ash Patel and John Robison (2000), Experience with personalization on Yahoo!, Association for Computing Machinery. Communications of the ACM, August, Vol. 43(8), 35-40.

13. Mobasher, Bamshad, Robert Cooley, and Jaideep Srivastava (2000), Automatic Personalization based on web usage mining, Association for Computing Machinery. Communications of the ACM, Aug, Vol. 43 (8), $142-151$.

14. Morris-Lee, James (2002), Customer communication: Does it pay?, Journal of Database Marketing, 
December, Vol. 10(2), 133-??

15. Nunes, Paul F. and Ajit Kambil, (2001), Personalization? No Thanks!, Harvard Business Review (April), Vol. 79(4), 32-34.

16. Peppers, Don and Martha Rogers (1993), The one to one future: Building relationships one customer at a time, Doubleday.

17. Reicken, Doug (2000), Personalized views of personalization, Association for Computing Machinery. Communications of the ACM, August, Vol. 43 (8), 26-??

18. Schubert, Petra and Peter Leimstoll (2004 ), Personalization of E-Commerce Applications in SMEs: Conclusions from an Empirical Study in Switzerland, Journal of Electronic Commerce in Organizations. Hershey: July-Sep 2004. Vol. 2, Issue 3, pg. 21-40.

19. Suprenant, Carol F. and Michael R. Solomon (1987), Predictability and Personalization in the service encounter, Journal of Marketing, Vol. 51(2), 86-97.

20. Wall Street Journal (2003), Dell pins hopes on services to boost profits, November 11.

21. Wind, Jerry and Arvind Rangaswamy (2001), Customerization: The next revolution in mass customization, Journal of Interactive Marketing, Winter, Vol. 15 (1), 13-32.

22. Wunder, Gene C. and George W. Wynn (1988), The Effects of Address Personalisation on Mailed Questionnaires Response Rate, Time and Quality, Journal of the Market Research Society, January, Vol. 30 (1), 95-100.

\section{APPENDIX A}

\section{Survey Questions}

Personalized marketing uses techniques that tailor advertising messages/content to a specific individual or subset of a target audience. This personalization is typically inserted into an ad through a process that is separate from the media. Customer/prospect information used for personalized marketing can either be explicit (e.g., provided through registration info or online keyword query) or implicit (e.g., specific pages visited at a Web site). Examples include letters in direct mail with individual names inserted into the salutation or a particular online ad served to an individual based on registration information collected during an earlier visit.

Which types of personalization methods have you used and which of the following are you evaluating for use in the current year? Please select all that apply.

1. Use clickstream data to dynamically change content presented to Web site visitors

2. Use registration data to dynamically change content presented to Web site visitors

3. Use keyword query data to dynamically change content presented to Web site visitors

4. Use collaborative filtering to classify a Web site visitor to a predefined customer/prospect segment and dynamically change content presented

5. Give Web site visitors control over Web site content by offering them a choice from a set of preferences

6. Use geographic personalization in online media: Tailor online marketing messages/content to customers/prospects based on geography

7. Use demographic personalization in online media: Tailor online marketing messages/content to customers/prospects based on geography

8. $\quad$ Address customers/prospects by name in electronic communications

Please rate your perception of the potential of these personalization methods to improve the effectiveness of your organization's marketing efforts. Answer from 1 to 7 for each, where a " 1 " means no potential and a " 7 " means high potential.

1. Increased customer retention

2. Increased margin of average sale

3. Overall increases in revenues 
4. More efficient use of customer/prospect time

5. More efficient use of partner time

6. More efficient use of employee time

$7 . \quad$ Reduced costs

8. Improved Web site registration rate

9. Increased number of Web site visitors

10. Increase in average time spent at site by prospects/customers

\section{NOTES}



NOTES 